\title{
On the Educational Task of Mediating Basic Values in an Individualist Society
}

\author{
By Lars Samuelsson* \\ Niclas Lindström ${ }^{\dagger}$
}

Besides the task of conveying information, methods and skills to their pupils, teachers are also expected to mediate certain basic values. In this paper we are interested in the educational task of mediating such values in societies imbued with individualist values and attitudes. As a background we use the results from the recurring "World Values Survey" (WVS) which maps the evaluative profile of citizens in about 80 different countries worldwide. The results from WVS reveal that Swedes in general stand out as remarkably individualist with respect to their reported value judgements. Hence, Sweden constitutes our example of an individualist society, i.e., a society whose members to a large extent share an individualist evaluative profile. One important feature of such an individualist evaluative profile is a tendency to regard questions of value as largely a private matter and to downplay the importance of ethics in general. Against this background we investigated the evaluative outlook of 134 Swedish teacher students, using questions from WVS as a point of departure. The results indicate that these students do not differ to any significant degree from the Swedish population in general as regards their evaluative outlook, and yet they are supposed to mediate both individualist and social basic values in their coming profession. The purpose of this paper is to make visible and problematize the tension between an individualist evaluative profile and the educational task of mediating a set of basic values. This tension, it is argued, poses special challenges for teachers and the teacher education in societies on the individualist side of the scale.

Keywords: basic values, evaluative profiles, mediating values, teacher education, value reproduction, individualism

\section{Introduction}

Just as teachers are supposed to convey information, methods and skills to their pupils, they are also expected to mediate certain basic values, although the precise content of these values varies between different societies. Depending on which country we look at, the task of mediating such values is either implicitly taken for granted within the country's educational system, or explicitly established in its regulatory documents. In Sweden, for instance, the curriculum for the upper secondary school states that "[e]ach and everyone working in the school should... encourage respect for the intrinsic value of each person and the environment we all share. [...] In accordance with the ethics borne by Christian tradition and Western humanism, this is to be

\footnotetext{
* Associate Professor, Umeå University, Sweden.

${ }^{\dagger}$ Associate Professor, Umeå University, Sweden.
} 
achieved by nurturing in the individual a sense of justice, generosity, tolerance and responsibility" (SNAE, 2013).

In this paper we are interested in the educational task of mediating such basic values in societies imbued with individualist values and attitudes. As a background, and for illustrative purposes, we use the results from the recurring "World Values Survey" (WVS), which maps the evaluative profile of citizens in about 80 different countries worldwide (WVS, 2016). It has become a common practice to present the results from WVS along two value dimensions: traditional versus secular-rational values, and survival versus self-expression values (e.g. Inglehart, 2006). In general, secular-rational and self-expression values are representative of an individualist evaluative profile, whereas traditional and survival values are representative of a more collectivist, or social, evaluative profile (these value dimensions and the connections between them are elaborated below). Hence, it is possible to use the results from WVS to roughly categorize countries as more or less individualist.

The results from WVS reveal that Swedes in general stand out as remarkably individualist with respect to their reported value judgements (WVS, 2015). Hence, Sweden constitutes our example of an individualist society, i.e., a society whose members to a large extent share an individualist evaluative profile. One important feature of such an individualist evaluative profile is a tendency to regard questions of value as largely a private matter something that should not be interfered with in the public sphere, e.g. in schools - and to downplay the importance of ethics in general (WVS, 2014).

Against this background we investigated the evaluative outlook of 134 Swedish teacher students, using questions from WVS as a point of departure. The results indicate that these students do not differ to any significant degree from the Swedish population in general as regards their evaluative outlook, and yet they are supposed to mediate both individualist and social basic values in their coming profession. The purpose of this paper is to make visible and problematize the tension between an individualist evaluative profile - where one tends to diminish the importance of ethical considerations and regard values largely as a private matter - and the educational task of mediating a set of basic values. This tension, it is argued, poses special challenges for teachers and the teacher education in societies on the individualist side of the scale.

\section{Theoretical Background}

\section{Evaluative Dimensions}

The results from the World Values Survey (WVS) provides an important background to this study. Although these results are commonly presented along the two value dimensions traditional versus secular-rational values, and survival versus self-expression values, it is more suitable for our purposes to present them in terms of collectivist versus individualist values, or simply collectivism versus individualism. The distinction between collectivism and 
individualism, in this context, is roughly based on 1. the extent to which the flourishing and opportunities of the individual is seen as dependent on the social group to which he or she belongs, and 2. whether the individual's right to self-fulfillment is regarded as more important than the flourishing of the group to which he or she belongs.

Individualism, in this respect, tends to put individual rights above social duties. Autonomy and self-fulfillment are considered important values as the individual to a large extent is seen as the sum of their own personal accomplishments (Inglehart \& Oyserman, 2004). These purported ideals are expressed in e.g. the notions of individual choice, openness to different ideas, self-expression and the denouncement of discrimination on any ground.

Collectivism, on the other hand, tends to put social duties above individual rights. Shared convictions, practices and goals are considered important as the individual is seen as a part (with a certain role) of a social group where it is commendable to make personal sacrifices to promote the common good. In the words of Inglehart and Oyserman (2004), "[t]he core element of collectivism is the assumption that groups bind and mutually obligate individuals." Collectivist ideals are expressed in e.g. the affirmation of the inclinations to work hard and do what you are told (obedience) and the awareness of a common cultural heritage.

Of course these are rough characterizations, and generalizations, of individualism and collectivism. Characterized in these ways these evaluative profiles should be seen as extremes that societies and individuals can approximate to a lesser or larger extent. However, the point of this short exposition is to establish that secular-rational values and self-expression values roughly correspond to individualist values, whereas traditional values and survival values roughly correspond to collectivist values.

Traditional values include the importance of family life, a sense of national pride, and religion as significant in peoples' lives. Secular-rational values, on the other hand, include such ideals as individualism, internationalism and absence of religious faith. Survival values center around trust and economic and physical security, whereas self-expression values stress ideals such as creativity, self-development, self-fulfillment and freedom of choice (see e.g. Inglehart \& Oyserman, 2004).

Somewhat generalized, traditional and survival values are more prevalent in less industrialized societies, while secular-rational and self-expression values are more prevalent in more industrialized societies. Accordingly, the latter societies are typically more individualist, while the former are typically more collectivist. Inglehart and Baker (2000) argue that as the populations of post-industrialized societies begin to take survival for granted, their priorities shift from an emphasis on "economic and physical security toward an increasing emphasis on subjective well-being and quality of life." That is to say, these populations begin to embrace individualist values to a larger extent and collectivist values to a lesser extent.

There are, no doubt, different ways to identify and conceptualize evaluative patterns. In this investigation we use the distinction between 
individualist and collectivist values as an analytical tool to categorize the evaluative outlook of teacher students. We do this in order to get an indication of which values that have been prevalent in their previous education and are likely to be present in their future teaching. By relating our results to those of WVS, this way of characterizing evaluative patterns also has the advantage of enabling a comparison with both national and international data.

\section{Teaching as a Social and Value Laden Practice}

A central point of departure for this study is the recognition that education is an essentially social activity, taking place in a cultural context imbued with shared values and norms (Säljö, 2014; Vygotsky, 1997). Not only are teachers supposed to help their pupils develop knowledge and competences; they are also expected to mediate values and make moral deliberations - and act upon them - as part of their everyday pedagogical practice. This is one reason why teaching has been labeled a "morally laden" activity and why ethics is commonly considered to be at the "heart of the teacher's disciplinary knowledge" (Bullough Jr., 2011; see also Campbell, 2013). Hence, even though education is primarily associated with the development of knowledge and competence, it is also, as a social activity, always associated with ideals, norms and values.

\section{The Reproduction of Value}

An additional point of departure for our study is the broadly embraced idea that teachers tend to reproduce values through their pedagogical practice; either consciously, as an explicit part of their professional endeavor, or unconsciously, as a result of their background (see Bourdieu \& Passeron, 1977; 1979). Even if the conditions for embracing the mediated values differ between different pupils, partly due to their different backgrounds, the overall result of a reproduction of values tends to be shared ways of thinking, valuing and acting (Bourdieu \& Passeron, 1977). Hence, one way of mapping the values that are reproduced within an educational system is to study the values embraced by pupils within that system. Several important studies have been carried out regarding the evaluative profile of pupils in different stages of the school system (see Apple, 1982) and of university students from the humanities (Bourdieu \& Passeron, 1979; 1977) and the social sciences (Bourdieu, 1996; Anteby, 2015; Holmqvist, 2015). For our purposes, it is particularly interesting to examine the evaluative profile of teacher students, as it reflects their previous education and will affect their future teaching.

\section{Methods and Research Procedure}

As explained above, the results from WVS can be used to roughly categorize societies as more or less individualist as regards the general 
evaluative profile of their populations. On this scale Sweden stands out as a remarkably individualist society. But even if Sweden stands out in this respect, it is not the only country of which it is correct to say that it is individualist in this sense (i.e. as characterized by the two value dimensions explained above). Several countries are positioned quite close to Sweden, for instance the other Nordic countries, the Netherlands, Switzerland, Australia and New Zeeland (WVS, 2015). In the upcoming discussion it is important to bear in mind that Sweden is used mainly as an example - and we believe that the educational systems in other individualist countries face similar challenges (even if they may embrace different models as regards the value conveying role of the educational system).

In order to be able to further relate the results from WVS to a teaching context in an individualist society, we investigated the evaluative outlook of a group of 134 Swedish teacher students. The students who took part in the survey were informed of its general purpose and invited to participate (voluntarily) under the condition that they could discontinue at any time. The survey was carried out via a web form distributed on the students' web-based teaching platform. For practical reasons, and in order to get a sufficiently high response rate, we had to limit the survey to relatively few questions. These were carefully chosen on the basis of two considerations highly relevant to our study: 1 . their relevance to a teaching context, and 2 . their ability to capture individualist and collectivist values.

There are two major reasons why teacher students constitute a particularly interesting group in this context: First, as students in the teacher education they are recipients of the basic values prevailing in the educational system of which they are to become a part (in the sense that they are supposed to come to embrace these values during their education so that they can mediate them to their own pupils once they have become teachers themselves). Second, when they become teachers they are also supposed to become mediators of these very values. Hence, in light of the assumptions 1. that teaching is a social and value laden practice, and 2. that values are reproduced within an educational system, it is of great interest to survey the evaluative attitudes of this particular group. As will be further developed below, an individualist evaluative profile may be problematic in relation to both these roles, i.e. as a recipient and as a mediator of basic values.

Before we take a closer look at our findings, two further notes are in place. First, we have only surveyed the views of teacher students from one Swedish university, namely Umeå University. However, we do not see any reason to believe that these students generally hold different evaluative views as compared to other Swedish teacher students - actually, the students at Umeå University come from all parts of Sweden. Second, the student group whose views we present below was at the beginning of their education to become teachers, and one might think that things may happen during the teacher education that systematically make the students change their views. In order to exclude that possibility, we surveyed a control group of 45 students at the end of their teacher education. It turned out that their answers to our survey 
questions did not differ in any significant way from the answers of the group of early students.

Below, in the Findings section, we present an illustrative sample of the results of our survey in two tables. The selection has been made on the grounds that it is directly relevant both to a teaching context and to the contrast between an individualist and a collectivist evaluative profile. In order to put our results in context we also present corresponding results from WVS. Firstly, we present WVS results from Sweden, since we compare the results from our survey of the evaluative profile of Swedish teacher students with the evaluative profile of Swedes in general. But we also need to put the results from Sweden in context in order to understand to what extent Sweden stands out as a particularly individualist society. For this purpose, we compare the Swedish results with the results both from a typical average country - here we choose Spain - and from one of the countries that are at the opposite end of the scale as compared to Sweden with respect to its evaluative profile - and here we choose Zimbabwe (WVS, 2015).

\section{Findings}

Table 1 shows answers the following query, borrowed from WVS. A list of eleven "child qualities" was presented to the respondents, who were asked to mark a maximum of five of these taken to be particularly important to encourage children to learn at home. In addition, the teacher students were asked which of these eleven qualities (a maximum of five) they took to be particularly important to encourage children to learn in school. For each of these qualities the table shows the percentage of individuals from each group that chose to mention that specific quality as particularly important. The results from WVS reveal that Swedes tend to embrace individualist qualities (e.g. independence and self-expression), while typical collectivist qualities (such as hard work and obedience) are mentioned as important by rather few. Qualities associated with a typical individualist outlook are marked "Ind.", while qualities associated with a typical collectivist outlook are marked "Col.". For some qualities it is not evident which type of profile they should primarily be associated with. Here the marks are put within brackets, and indicate which type of profile these respective qualities are probably most naturally considered to belong to. 
Table 1. Child Qualities

\begin{tabular}{|l|c|c|c|c|c|c|}
\hline Profile & Child qualities & $\begin{array}{c}\text { Learn } \\
\text { home, } \\
\text { Zimb. }\end{array}$ & $\begin{array}{c}\text { Learn } \\
\text { home, } \\
\text { Spain }\end{array}$ & $\begin{array}{c}\text { Learn } \\
\text { home, } \\
\text { Swe. }\end{array}$ & $\begin{array}{c}\text { Learn } \\
\text { home, } \\
\text { t.-stud. }\end{array}$ & $\begin{array}{c}\text { Learn } \\
\text { school, t.- } \\
\text { stud. }\end{array}$ \\
\hline Ind. & Independence & 39.1 & 43.1 & 70.3 & 61.9 & 65.7 \\
\hline Col. & Hard work & 76.0 & 66.6 & 13.8 & 11.2 & 26.9 \\
\hline (Ind.) & $\begin{array}{c}\text { Feeling of } \\
\text { responsibility }\end{array}$ & 43.1 & 78.6 & 82.5 & 82.1 & 83.6 \\
\hline (Ind.) & Imagination & 13.3 & 24.8 & 46.7 & 44.0 & 43.3 \\
\hline (Ind.) & $\begin{array}{c}\text { Tolerance and } \\
\text { respect for other } \\
\text { people }\end{array}$ & 63.8 & 74.1 & 87.0 & 94.0 & 90.3 \\
\hline (Col.) & $\begin{array}{c}\text { Thrift, saving } \\
\text { money/things }\end{array}$ & 25.1 & 29.6 & 38.6 & 34.3 & 13.4 \\
\hline (Col.) & $\begin{array}{c}\text { Determination, } \\
\text { perseverance }\end{array}$ & 49.4 & 37.5 & 33.6 & 30.6 & 41.8 \\
\hline Col. & Religious faith & 59.6 & 10.6 & 4.4 & 3.7 & 0.7 \\
\hline (Col.) & Unselfishness & 29.5 & 35.0 & 30.4 & 41.0 & 40.3 \\
\hline Col. & Obedience & 70.1 & 31.4 & 12.2 & 17.2 & 9.0 \\
\hline Ind. & Self-expression & 20.6 & 8.3 & 37.6 & 28.4 & 50.7 \\
\hline
\end{tabular}

Sources: Columns 1-3: World Values Survey Wave 6: 2010-2014, http://bit.ly/1pgK8T5; Columns 4-5, our survey of 134 Swedish teacher students.

The particular challenge that faces teachers in the teacher education can be illustrated by the following findings from WVS and our survey. The question asked here was to what extent the respondents considered themselves similar to the following person: "It is important to this person to always behave properly; to avoid doing anything people would say is wrong" (Table 2).

Table 2. Behave Properly

\begin{tabular}{|l|c|c|c|c|}
\hline Behave Properly & Zimb. & Spain & Swe. & t.- stud. \\
\hline Very much like me & 43.3 & 22.7 & 10.2 & 6.7 \\
\hline Like me & 31.8 & 40.0 & 23.5 & 15.7 \\
\hline Somewhat like me & 15.0 & 22.5 & 21.3 & 26.9 \\
\hline A little like me & 7.8 & 8.8 & 20.3 & 23.1 \\
\hline Not like me & 1.7 & 4.0 & 16.0 & 20.9 \\
\hline Not at all like me & 0.4 & 1.0 & 7.8 & 6.7 \\
\hline $\begin{array}{l}\text { No answer/Don't } \\
\text { know }\end{array}$ & 0.0 & 0.9 & 0.9 & 0.0 \\
\hline
\end{tabular}

Column 4, our survey of 134 Swedish teacher students.

As Table 2 shows, Swedes in general and Swedish teacher students in particular identify with this person to a much lesser degree than e.g. people in Spain and Zimbabwe.

\section{Results}

If we start by looking at the teacher's role as a mediator of values, it is 
clear that there are some (individualist) values that the Swedish teacher students generally should have no problems being motivated to mediate to their future pupils. Both "feeling of responsibility" and "tolerance and respect for other people" score very high among this group $(83.6 \%$ and $90.3 \%$ respectively) (Table 1). But values that are arguably more important for cooperation and group success score much lower. Hence, "obedience" and "hard work" are not seen as very important at all (9.0\% and $26.9 \%$ respectively) (Table 1). In addition, qualities that do not fit so well with the task of mediating a particular set of values are getting comparably high scores among the Swedish teacher students and Swedes in general. Putting "independence" $(65.7 \%)$ and "self-expression" (50.7\%) above "obedience" (9.0\%) and "unselfishness" (40.3\%) as qualities important to learn in school (Table 1) may make it difficult to mediate a particular set of basic values, including e.g. (as in the case of the Swedish curriculum) "respect for the intrinsic value of each person and the environment we all share" and "solidarity between people" (SNAE, 2013). ${ }^{1}$

If we now turn to the teacher students' role as recipients of a certain set of basic values, the results in Table 1 are not in themselves equally informative. But here other survey results turn out to be helpful. We asked the teacher students to what extent they had trust in their own teachers. Of those who replied, only $9 \%$ reported great trust in their teachers, while comparably many, $28 \%$, stated that they did not have any considerable trust in their teachers. Perhaps even more telling is the result from the related question of to what extent the teacher students let their choices be influenced by their teachers. Here only $4 \%$ of those who answered claimed to have let their choices be influenced by their teachers to a very large extent, while as many as $58 \%$ stated that they did not let their choices be influenced by their teachers to any notable degree.

It is not entirely clear how one should interpret the findings presented in Table 2, but put in relation with the data presented in Table 1, a natural interpretation seems to be that Swedes, like people in other typical individualist societies, in a sense tend to downplay the importance of ethics (only $6.7 \%$ of the surveyed teacher students and $10.2 \%$ of the surveyed Swedes identify to a large extent with a person to whom it is important to behave properly; the corresponding number for Zimbabweans is $43.3 \%$ and for Spaniards 22.7\%) (Table 2).

\footnotetext{
${ }^{1}$ Note that "respect for the intrinsic value of each person", as mentioned in the curriculum for the Swedish school, is arguably quite different from the notion of "tolerance and respect for other people" figuring in the surveys (although here it is of course difficult to know how different respondents interpret this latter notion). While "tolerance and respect for other people" is plausibly understood as a liberal "value" [roughly that of letting people lead their own lives, associated with so called negative rights (see e.g. Wenar, 2015)], "respect for the intrinsic value of each person" is arguable something that endows agents with positive duties, such as helping people in need (this interpretation is strengthen by the fact that the intrinsic value of nature is mentioned in the same sentence in the curriculum).
} 


\section{Discussion}

Probably most Swedes, like other people, want to behave in a way that they themselves can stand for and take to be justified, but generally they do not seem to want to identify this behavior with any particular view of "behaving properly". Rather, they seem to want it to be simply another manifestation of their own individual choices, whereas they regard a person "behaving properly" as someone who is uncritically and non-independently following a certain set of external rules. As noted above, an important feature of a typical individualist evaluative profile is that values are regarded as largely a private matter something that should not be interfered with in the public sphere, e.g. in schools. However, as teachers are supposed to follow and also mediate a set of external rules or values (external in the sense that they are not up to each individual to decide) this view fits badly with the value mediating aspect of the teacher's mission.

Combined with the affirmative attitudes towards independence and selfexpression accounted for above, we think these results indicate a view according to which values are seen as something to be formed independently, and not collectively, in and as a group. Here we want to emphasize that we do not think there has to be anything wrong with this view as such; whether and to what extent it is reasonable plausibly depends on the nature of the group to which one belongs. But in many cases it is probably true that one's evaluative views and reasoning benefit from interactions with others, and that a common enterprise within a group of finding solid and defensible values is preferable to searching for them in isolation (see e.g. Samuelsson \& Rist, 2016). The main point here, however, is simply that the individualist outlook among pupils or students (and among the teachers themselves) provides a challenge for the teacher whose task it is to mediate a certain set of basic values, whether in the teacher education or in compulsory school or upper secondary school.

\section{Concluding Remarks}

In this paper we have presented the tension between an individualist evaluative profile and the ethical and educational task of mediating a set of basic values. We have also revealed and discussed the challenge that this tension poses for teachers, and in particular the teacher education, in individualist societies. As both recipients and mediators of such values teacher students constitute a particularly interesting group to investigate. Our survey confirms that Swedish teacher students generally embrace individualist values, such as independence and self-expression, while they tend to reject collectivist values, such as hard work and obedience. Furthermore, it is common among the members of this group not to trust or let their choices be influenced by their teachers to any significant degree. Perhaps the most striking result is that these teacher students do not tend to identify with a person for whom it is important to behave properly. Thus, it seems common among teacher students in an 
individualist society not to regard themselves, or teachers in general, as role models. Of course, this evaluative profile fits badly with the task of mediating a certain set of basic values to one's pupils.

Given these results we think it is important that teachers and teacher students, in particular in individualist societies, become more aware of the tension between an individualist evaluative profile and the task - implicit in almost all education - of mediating a set of values to one's pupils. Indeed, it is not sufficient to just be aware of this tension; teachers have to be able to reflectively relate themselves and their practice to the value-conveying task of their profession. What is needed in order to raise such awareness? Here we believe that some important steps can be taken within the teacher education:

We suggest that (more) space is dedicated within teacher educations for 1 . identifying individualist and collectivist values in the pedagogical practice; 2 . problematizing one's own evaluative views in relation to the views held by others, e.g. in other societies; 3 . putting these considerations in relation to the educational task of mediating certain basic values, for instance values established in regulatory documents. Here we think that the results from WVS can provide an eye-opening and challenging point of departure (see further Lindström \& Samuelsson, 2016). In order to fill in the details of this approach, however, more research is needed, both concerning the values held by teachers and teacher students in different societies, and concerning the pedagogical challenge of how to best prepare teacher students for the task of mediating values in their coming profession in a reflective and conscious way.

\section{References}

Anteby, M. (2015). Manufacturing morals: The values of silence in business school education. Chicago: University of Chicago Press.

Apple, M. W. (Ed.) (1982). Cultural and economic reproduction in education. London: Routledge \& Kegan Paul.

Bourdieu, P. (1996). The state nobility. Oxford: Blackwell.

Bourdieu, P., \& Passeron, J-P. (1977). Reproduction in education, society and culture. London: Sage Publications.

Bourdieu, P., \& Passeron, J-P. (1979). The inheritors, French students and their relation to culture. Chicago: The University of Chicago Press.

Bullough Jr., R. V. (2011). Ethical and moral matters in teaching and teacher education. Teaching and Teacher Education, 27(1), 21-28.

Campbell, E. (2013). The virtuous, wise, and knowledgeable teacher: Living the good life as a professional practitioner. Educational Theory, 63(4), 413-429.

Holmqvist, M. (2015). Djursholm: Sveriges ledarsamhälle [Djursholm: Sweden's leader society]. Stockholm: Atlantis.

Inglehart, R. (2006). Mapping global values. In Y. Esmer \& T. Pettersson (Eds.), Measuring and Mapping Cultures: 25 Years of Comparative Values Surveys. Leiden: Brill.

Inglehart, R., \& Baker, W. E. (2000). Modernization, cultural change, and the persistence of traditional values. American Sociological Review, 65(1), 19-51. 
Inglehart, R., \& Oyserman, D. (2004). Individualism, autonomy and self-expression. In H. Vinken, J. Soeters \& P. Ester (Eds.), Comparing Cultures. Leiden: Brill.

Lindström, N., \& Samuelsson, L. (2016). Using interactive tools and teaching methods to prepare teacher students for the task of conveying basic values. In L. G. Chova, A. L. Martínez, \& I. C. Torres (Eds.), EDULEARN16 Proceedings: 8th International Conference on Education and New Learning Technologies. Valencia: IATED Academy.

Samuelsson, L., \& Rist, L. (2016). Stakeholder participation as a means to produce morally justified environmental decisions. Ethics, Policy \& Environment, 19(1), 76-90.

SNAE (The Swedish National Agency for Education). (2013). Curriculum for the upper secondary school. Stockholm: Skolverket. Retrieved from http://bit.ly/1U TF5aR.

Säljö, R. (2014). Lärande i praktiken: Ett sociokulturellt perspektiv [Learning in Practice: A Sociocultural Perspective]. Lund: Studentlitteratur.

Vygotsky, L. (1997). Interaction between learning and development. In M. Guavain \& M. Cole (Eds.), Readings on the Development of Children. New York: W.H. Freeman \& Co.

Wenar, L. (2015). Rights. In E. N. Zalta (Ed.), The Stanford Encyclopedia of Philosophy (Fall 2015 Edition). Retrieved from http://stanford.io/2fZbp2M.

WVS (World Values Survey). (2014). Wave 6: 2010-2014. Retrieved from http://bit. $1 \mathrm{y} / 1 \mathrm{pgK} 8 \mathrm{~T} 5$.

WVS (World Values Survey). (2015). Cultural Map. Retrieved from http://bit.ly/1f7 $\operatorname{chhX}$.

WVS (World Values Survey). (2016). World Values Survey. Retrieved from http://bit. ly/1FoxcIQ. 
